\title{
Service quality study in the property and casualty insurance market using the Quality Function Deployment methodology
}

\author{
Jordi Escayola \\ Universitat Ramon Llull IQS School of Management Ringgold Standard Institution \\ Economia y Empresa \\ Jesús Tricás \\ Universitat Ramon Llull IQS School of Management Ringgold Standard Institution \\ Economia y Empresa
}

Received August 5, 2016; accepted September 30, 2016.

\begin{abstract}
The aim of this project is to study the dimensions of service quality in non-life insurance market, applying the Quality Function Deployment (QFD) methodology.

To achieve the purpose of the paper, a specific service quality scale was developed to reflect the most important service quality elements in the insurance industry. For the first time in any insurance market or insurance service quality research, the Insurance Service Quality Function Deployment (ISQFD) matrix was developed especially for the insurance sector. Furthermore, the SIQUAL scale has been developed which is specifically designed to analyse service quality in the insurance industry.

We interviewed over 300 insurance customers (mainly car and home insurance policy holders) and 17 insurance experts -including company directors, researchers, public institution members, private institution members and consultancy directors from the insurance sector.

By applying what we propose in this research study, insurance companies can develop their business and focus their actions on what is more efficient in the long term, increase their customers' satisfaction and loyalty. This research represents the first QFD analysis in the European insurance market and it is the first study based on a specific service quality scale, establishing a solid basis for future research in insurance service quality.
\end{abstract}

\section{KEYWORDS}

Property and casualty, Quality Function Deployment, Insurance, Service Quality. 


\section{Introduction}

Companies use aggressive marketing strategies to attract new customers and to increase their market share at the expense of competitors. They develop defensive strategies to protect their products and markets from the competition by maximizing customer retention under certain cost constraints (Ennew and Binks, 1996; Roberts, 2005). Small increases in the customer retention rate can generate considerable improvement in profitability as the cost of attracting new customers is higher than the cost of retaining new customers (Lombardi, 2005).

In insurance, high retention rates are closely related to the economic performance of companies (Diacon and O'Brien, 2002). A large number of insurers consider retention to be the most important determinant of economic success (Moore and Santomero, 1999).

As in other industries, the selling cost of an insurance policy is not recovered unless the policy is renewed for at least three or four years (Zeithaml et al., 1996). Because loyalty is essential in the insurance business, Shlesinger and Graf von der Shulenburg (1993) suggested that corporate image and service quality influence the customers' decisions to choose insurers and affect the price customers are prepared to pay for a policy. A moderating variable between service quality/ customer satisfaction and economic performance is loyalty (Tsoukatos and Rand, 2006). Loyalty is the extent to which customers wish to keep their relationship with a supplier, and usually results from how much they believe that the value they receive from this supplier is higher compared to what they would receive from others.

Not all insurance products have the same characteristics, and it is easy to identify differences between life, health, and property and casualty insurance products and services. In property and casualty insurance, the longer customers remain with a company the less likely they are to submit claims (Peppers and Rogers, 2014). According to the points stated above, customers become more profitable over time. The industry considers that understanding customer behavior after the initial purchase will help insurers to maintain longer customer-insurer relationships (Harrison, 2003).

Despite the importance of the Spanish insurance industry, it has been the object of scant attention in business research literature. 
It is important to take into consideration the high level of competition in the insurance market - especially as far as property and casualty insurance products are concerned, as they are based on the features of competitive markets (Joskow, 1973).

Because of the fact that an insurance policy is usually characterized by a substantial delay between purchase and use, many of its features are not immediately evident. In most cases, customers will not be fully informed and aware of the exact features of their insurance policy before they actually need to use it, i.e. when they need to file a claim. The most important reason to purchase an insurance policy is the amendment of damages - which may or may not occur in the duration of an insurance contract (Wells and Stafford, 1997; Anderson and Skogh, 2003). This makes the claim settlement procedure the most critical incident of insurances. Only then can customers actually assess the value of the service they bought some time ago. This distinguishes insurance from the majority of services, for which production and consumption occur simultaneously (Zeithaml et al., 1988). As a logical consequence, it is important to consider that not all customers are going to file a claim.

According to Toran (1993), quality should form the basis of all activities involved in the insurance industry, because customers want higher quality service through responsive agents with better contact and personalized communications from the insurer. Accurate transactions and quickly solved problems are also services expected by customers (Pointek, 1992).

Taylor (2001), in his study on service recovery analysis in the insurance industry, noted that quality of service and customer satisfaction and loyalty are fundamental for the survival of insurers. He further stated that the development of close relationships with customers, high-quality after-sales services, and good relationships with customers can lead to highly positive results for the insurers.

King (1992) established the following four important insurance quality factors: financial stability of the company, reputation of the insurer, agent integrity, and quality of information and guidance from the agent.

Curiously, some researchers define insurance quality as the insurers' willingness to compensate sincere customers (Anderson and Skogh, 2003). Others confuse quality and generosity, the latter being insurers' readiness to compensate for more than a court would order (Roos, 1981). The tendency of insurers not to adequately perform regarding their 
customers' perceptions of quality creates problems to them, as the markets are extremely competitive and continuously become more so (Taylor, 2001).

We have not found any previously published studies on using Quality Function Deployment in any European market. Despite the global influence of the insurance sector, very few research focus on-the relationships between customer expectations and the insurance company's actions.

The particular characteristics of the insurance business reflect that it is crucial to improve service quality perception, and this research proposes the application of QFD in order to improve insurance services. As a result, customer satisfaction and loyalty will increase by discovering which the most important HOWs are in order to achieve customer expectations. This is the main aim of this research.

The secondary objective is to analyze the importance of service quality dimensions in the Spanish property and casualty insurance market by studying the importance of the WHATs.

In addition, certain improvements in the property and casualty insurance sector-service quality and retention - could have a strong impact on the results of insurance companies, and customers would be provided with a better and more efficient service in accordance with their expectations.

\section{Literature review}

\subsection{The Voice of the customer}

Applying the QFD methodology implies obtaining information about WHAT the customer's expectations are. In order to get this information, we will use the voice of the customer (VOC) as the WHATs for the QFD structure.

Traditionally, customer voices have been considered a critical resource for firms (Lee et al., 2000). This is because VOC includes expectations related to customer needs and requirements, and these expectations can help firms to improve their products or services. Research on VOC started developing based on Parasuraman's research. He stated that VOC can be collected from customer recognition and customer surveys, and emphasized the importance of the VOC collection method (Parasuraman et al., 1988). They proposed to use VOC as an input to Quality Function Deployment (QFD) in order to formalize the process of listening to the customer. 
A generally accepted point of view is that VOC should be considered as a gift to help firms develop new products or services that meet the needs of their customers (Barlow and Moller, 2008; Denove and Power, 2007). Walker and Baker (2000) stated that one of the crucial elements of insurance quality is the understanding of customers' expectations, for instance by VOC, because their expectations serve as standards against which service performance is measured.

Moreover, it is important to stay in touch with realistic and current customer expectations, because they are dynamic and highly influenced by other factors (Ghobadian et al., 1993). According to Gans (2002), if an organization does not understand customer expectations, any required actions taken to improve the quality of the products and services are unable to succeed.

In this particular study, we take as a reference the items from a previous research study analyzing the Greek insurance market (Tsoukatosand and Rand, 2006), which was in its turn based on an earlier study in of the Greek and Kenyan markets (Tsoukatos et al., 2004). We adapted it to the Spanish insurance market based on the opinions of insurance experts and expert market research-professors. The interviewees represented an important part of the insurance sector (insurance company workers, brokers, academics and members of public institutions).

\subsection{Quality Function Deployment (QFD)}

QFD is a tool to help understand customer needs, through which one can design or improve services and products in accordance with the requirements of customers. "Quality Function Deployment" is a translation from the Japanese characters "him shitsu" (quality), "kinou" (function), and "ten kai" (development).

Researchers such as Sullivan (1986), Hauser and Clausing (1988), Zairi and Youssef (1995), Chan and Wu (2002), and Terninko (1995) have discussed the benefits of QFD. QFD is probably the most important management tool developed to assure quality in new or improved products and services. It is an important aspect because product and service development implies an increase in sales (Krishnan and Ulrich, 2001). In fact, both production and service industries could use its benefits, as expressed in the research literature on the implementation of QFD (Cristiano et al., 2000). QFD is a very interesting tool to obtain relationships between elements in strategic planning, necessary for organizations. Devadasan et al., (2006) affirm that by using QFD, companies would 
reduce time spent designing products, and Franceschini (2001) defends using QFD in order to improve products in accordance with customer needs.

QFD is used in various fields for determining customer needs (Stratton, 1989), for developing priorities (Han et al., 1998), formulating annual policies (Philips et al., 1994), benchmarking (Pfohl and Ester, 1999), and environmental decision-making (Berglund, 1993).

As a result, we conclude QFD is a useful tool to study how companies could improve their product/ service quality in accordance with customer expectations and the technical aspects of the insurance product/ service.

To this end, we adapted the traditional process of QFD to enable the construction of Insurance Service Quality Function Deployment (hereinafter ISQFD), which consists of the sections detailed below:

Section 1: the WHATs, consisting of a list of corporate clients' expectations in relation to their external legal advisers, as well as the relative importance of each of the identified expectations to corporate clients (the weight of the WHATs).

Section 2: the HOWs, consisting of the resources an insurance company needs to improve in order to satisfy the WHATs (client expectations).

Section 3: The Relationship matrix, providing mapping of the level of impact of each of the HOWs (insurance company resources) regarding each of the WHATs (client expectations).

Section 4: The Contribution values, identifying the influence of each of the HOWs in the overall corporate client satisfaction with regard to their insurance service. The resources obtaining the highest contribution values are critical for competitive quality and hence represent strategic quality resources.

Section 5: The Roof. This matrix is designed to show the impact of each one of the resources on the rest. It is a bidirectional impact, where the interdependence between the resources is determined. This section provides relevant information on the way in which insurance companies enhance relevant resources by interlinking them with other 
resources, and hence with regard to the dominant logic in a particular company or industry.

\section{Research methodology}

A deductive method was used, as previous studies served as a theoretical basis to develop this research.

Our study focuses on the construction of the first matrix in the QFD structure, which analyzes the relationship between the WHATs and HOWs and the construction of section 5 , the roof.

While developing our research, and more particularly during the process of obtaining the key points to construct the QFD matrix, we used quantitative and qualitative research methodologies.

On the one hand, to construct the set of WHATs and HOWs, the interviews with different insurance experts were the qualitative part of the research. On the other hand, the information obtained from surveys (the weight of the WHATs) constituted the quantitative part of the research.

\subsection{Creation of the WHATs}

As we mentioned earlier, the WHATs of QFD in this research are based on the Tsoukatos and Rand (2006) research studies and have been adapted to the Spanish insurance market. We decided to include 21 items as well as "Price" and "Solvency margin", because, if we take into consideration the recent economic crisis, the price is of utmost importance in customer's responses. As a result, customers provided answers in 5-point Likert scales for each of the 22 service attributes of the survey. In order to obtain the final 21 WHATs, we grouped similar concepts keep the survey as short as possible, while maintaining the diversity of concepts.

It is necessary to adjust the items used in the WHATs (voice of the customer), because, as Furrer et al., (2000) established, the importance of SERVQUAL (Parasuraman et al., 1988) dimensions - the primary theoretical basis of this research and the basis of the GIQUAL scale- vary in people from different cultural backgrounds. Because of this, it is crucial to obtain realistic and time-consistent items that measure the real service quality dimensions of the insurance service. 
It is common for companies to conduct customer satisfaction surveys to know their customers' point of view. Improvements on the basis of such surveys are usually considered to be enhancements in the competitive position of the firm, which ultimately result in better offerings and better customer service (Frank and Enkawa, 2007).

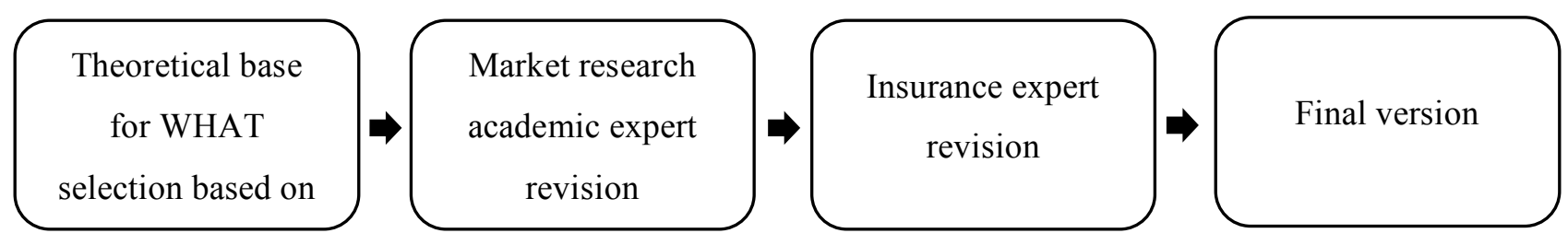

Figure 1. Graphical summary describing the creation process of WHATs

Finally, some differences but not significant changes with regard to the original GIQUAL scale were observed. The final set of items to be analyzed were: "Technological development of the insurance company", "Image of the insurance company", "Personal image and presence of employees", "Advertising", "Price", "Compliance with agreed contract", "Products which satisfy customer needs", "Contracts with understandable service conditions", "Interest in solving the problems", "Clear documents presenting no errors or ambiguities", "Information about when services requested by customers are to be carried out", "Speed and efficiency of the service", "Willingness to help and respond to customers", "Confidence inspired in the customer", "Adequate time for solving the claims", "Courtesy", "Adequate knowledge of the employees", "Personalized service", "Opening hours", "Defending the interests of the client and acting in good faith", "Understanding of the specific needs of the customer".

Although the initial set of WHATs was designed to analyze another insurance market, according to the opinions of different insurance experts, we may assure the final list is appropriate to analyze service quality items in the Spanish insurance market. Some elements of the initial WHATs list (Tsoukatos and Rand, 2006) were not considered, others were grouped and the item "Price" was included according to the experts' opinions. This final list of WHATs form the SIQUAL scale which is specific for analyze service quality in property and casualty insurance.

The weight of the WHATs was obtained by a set of 305 surveys completed by insurance customers. The majority of them were filled out online using Surveymonkey software. As a pretest, two insurance experts and a reduced number of customers were interviewed in 
order to detect inconsistencies or establish potential improvements. Data were collected between February and June 2016.

In the sample, $40 \%$ of the customers required the services of the insurance company in the previous-two years previous to completing the questionnaire.

\subsection{Creation of the HOWs}

In order to obtain the HOWs, we interviewed different experienced insurance experts in the Spanish insurance sector. After carrying out several one-hour interviews, we grouped the concepts discussed and selected those that appeared more frequently. In addition, we included the concept "Knowledge of the market", because we thought it would be important to understand what was going on in the sector and what direct competitors were doing.

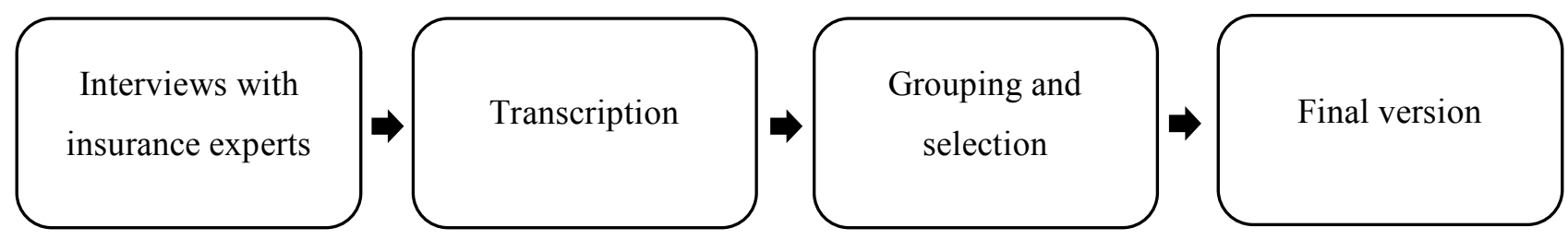

Figure 2. Graphical summary describing the creation process of the HOWs

An interesting point to highlight is the similarity between the interviews with experts. They agreed substantially in their opinions regarding the possible actions an insurance company should take in order to obtain better satisfaction results.

The final set of HOWs were the following1: "Product offering", "Technology", "Call center service", "Pricing systems", "Marketing and advertisements", "Solvency margin", "Underwriting processes", "Documents and conditions", "Additional services offering", "Knowledge of the market", "Training of employees", "Professionals", "Working environment", "Knowledge about the insured risk", "Relationship with brokers", "Active communication with customers", "Claims management", "Risk management", "Coordination between departments", "Orientation to the customer", "Integrity of employees".

\footnotetext{
${ }^{1}$ By chance the same number was obtained in the WHAT's and HOW's set.
} 


\subsection{Construction of the QFD Matrix}

After obtaining the WHATs and HOWs, the QFD matrix was constructed in accordance with the results obtained and tested in 17 interviews to insurant experts (CEOs, directors, technical mangers, business area managers, brokers, researchers, members of public institutions...). Two interviews were used as a pretest, which concluded that the questionnaire was a clearly understood matrix and did not present any significant errors, so no modifications were made. Data were collected between March and September 2016. During the interviews, experts completed the matrix and we observed a relative certain level of consistency in their answers. In general, and as previous analysis showed, they provided similar opinions. During the interviews, experts had to evaluate the correlation between each WHAT and each HOW as follows:

- $\quad 0$ : no correlation at all

- $\quad$ 1: low correlation

- 3: medium correlation

- 9: high correlation

\subsection{Construction of the Roof}

During the interviews designed to obtain the QFD matrix, insurance experts were asked about the correlation between the HOWs. In this case, they had to provide us with their opinion regarding the correlation between elements manageable by insurance companies. Due to the fact that the QFD matrix exercise is rather difficult and time-consuming, we decided to reduce the complexity of the roof by asking experts whether they found a correlation or not. The results were obtained as follows:

- 0: no correlation

- 1: positive correlation

The possibility of including negative correlations was not considered so as to simplify the analysis. Data were collected between March and September 2016 simultaneously with the QFD matrix results. 


\section{Results}

\subsection{Importance of the WHATs}

In this section, results show which the most important service quality items (WHATs) are for insurance customers. According to the results of the survey, the majority of the items are highly valued, and it is difficult to notice a subset of items as significantly more important than others. This implies that the item selection was successful.

Results in Figure 3 clearly show that the less important items are: advertising, personal image of employees and technological development of the insurance company. Customers are probably expressing the fact that these features do not reflect the "essence" or the basics of a property and casualty insurance contract, which is supposed to provide customers with a solution according to previous contract conditions. All these items reflect the efforts of insurance companies to transmit a comfortable and interesting image of the services offered. However, in the end, these particular items do not contribute to improving the quality of the service.

In contrast, it is very clear that customers perceive that such as speed and efficiency of the service, interest in solving the problems, and compliance with the contract are of great importance. Taking into consideration the potential significance of insured risks in the property and casualty insurance business, it seems logical that customers are interested in obtaining ethical, clear, and fast solutions if required.

Surprisingly, items such as "Price", "Courtesy" and "Products which satisfy customer needs", which a priori seem to be crucial for quality in the insurance business, are not highly valued. However, it is important to highlight that in the past few years, due to the economic crisis, the prices of the majority of insurance products in Spain decreased. This probably strongly affects the perception of price, which customers do not consider to be a significant item. 


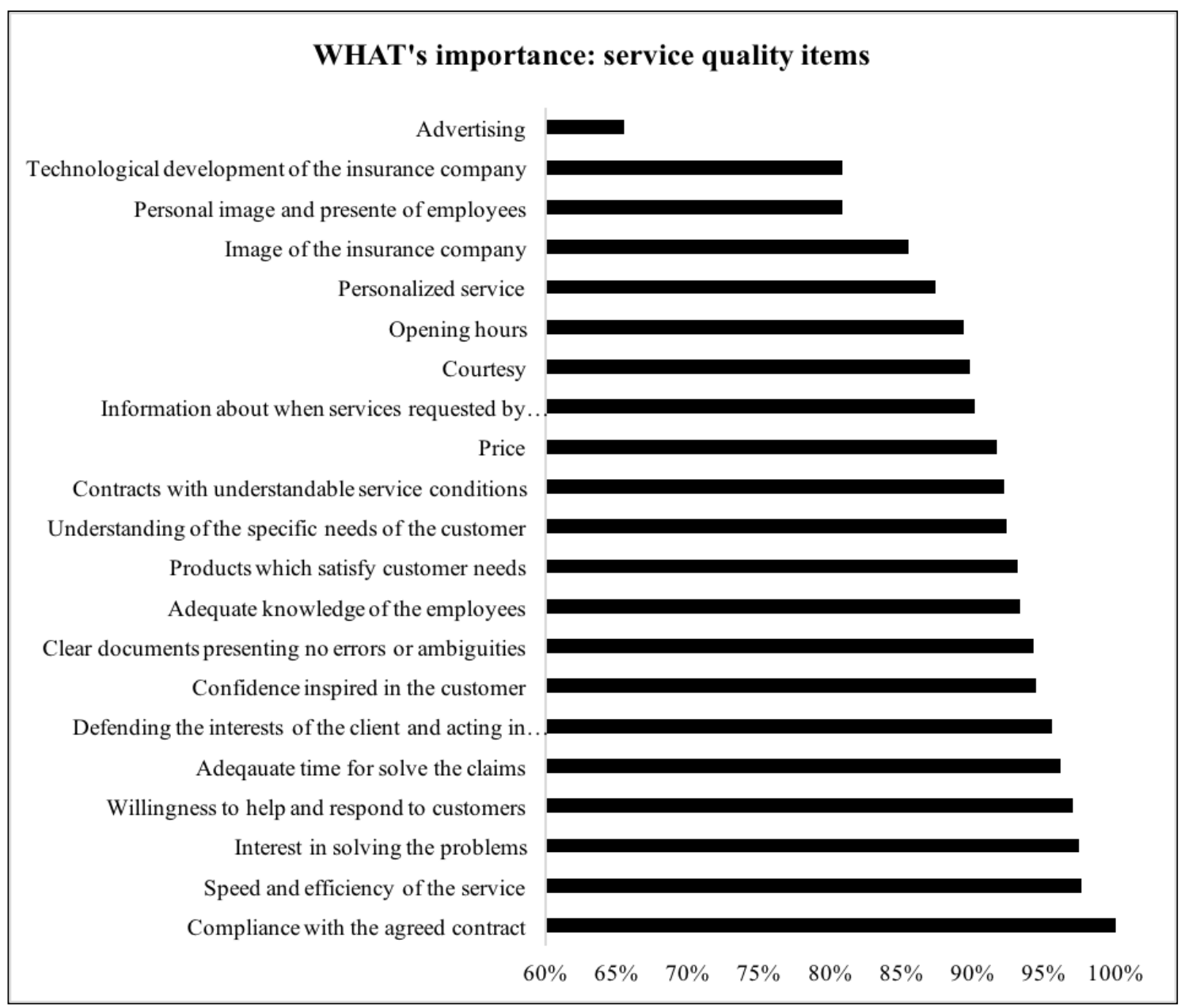

Figure 3. Results of the normalized importance of the WHATs

\subsection{QFD matrix}

The highlighted results are those considered significant - with an average higher or equal to 8 , and a standard deviation less or equal to 2.5 . Taking into consideration the sample size of experts (17 interviewed insurance experts), consistent results were obtained using this scale.

It is important to mention that the figures only appeared as significant when there was strong evidence that this relationship existed, based on expert opinions.

Some potential improvements that had a remarkable impact on the image of insurance companies were very significant in terms of global contribution. It seems clear that if companies improve the most requested HOWs, such as "active communication with customers" and "orientation to the customer", the image of the insurer improves.

By enhancing customer orientation, experts may expect an important effect on all concepts related to customer support, advertisement and the image of the company which is important due to the nature of the business. Investments in active communication 
with customers improve the customer's feeling of being understood by insurance companies, the perception of personalized service, as well as the insurer's image.

An interesting point to consider is the high correlation between "Technology" and the efficiency and speed of the service, which is critical to solve the overwhelming majority of claims in certain property and casualty insurance business lines.

Investment in "Claims management" is expected to improve the image of the insurance company, the commitment with the customer, and the efficiency of the service.

"Integrity of employees", as expected, has a strong correlation with corporate image and with transmitting security to customers. It is probably a required condition for other concepts, and if it is not highly correlated with other customer requirements it is because it has been "taken for granted".

According to the opinions of the experts interviewed, by improving "Solvency margin" and "Underwriting processes", companies should expect no significant improvements in service quality perception.

Investing in "Training of employees" is expected to generate moderate changes in some particular service quality items, but it is not significant enough to be considered crucial.

Only efficiency of the service and knowledge of employees would increase significantly.

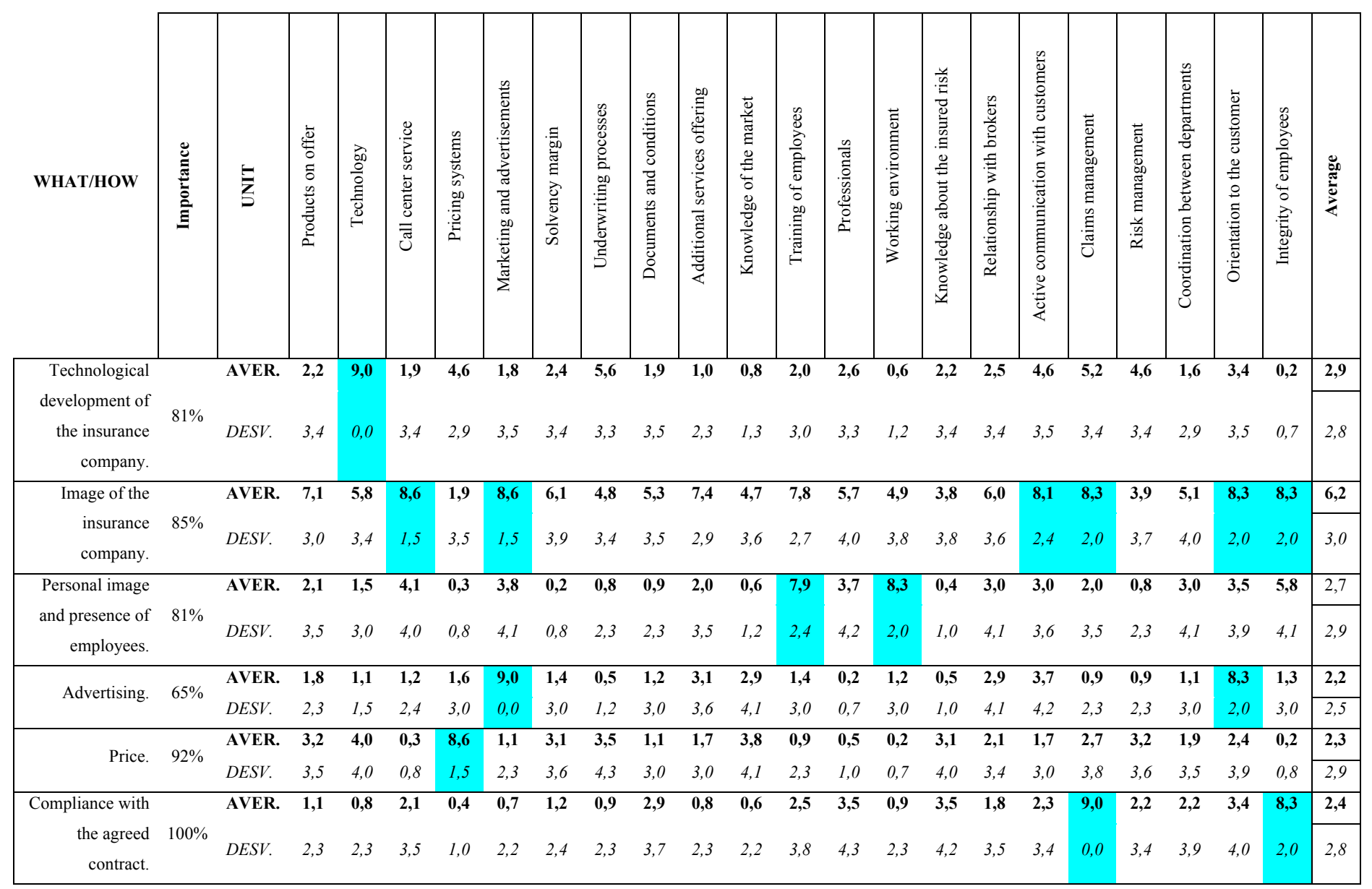


Service quality study in the property and casualty insurance market using the Quality Function

Deployment methodology

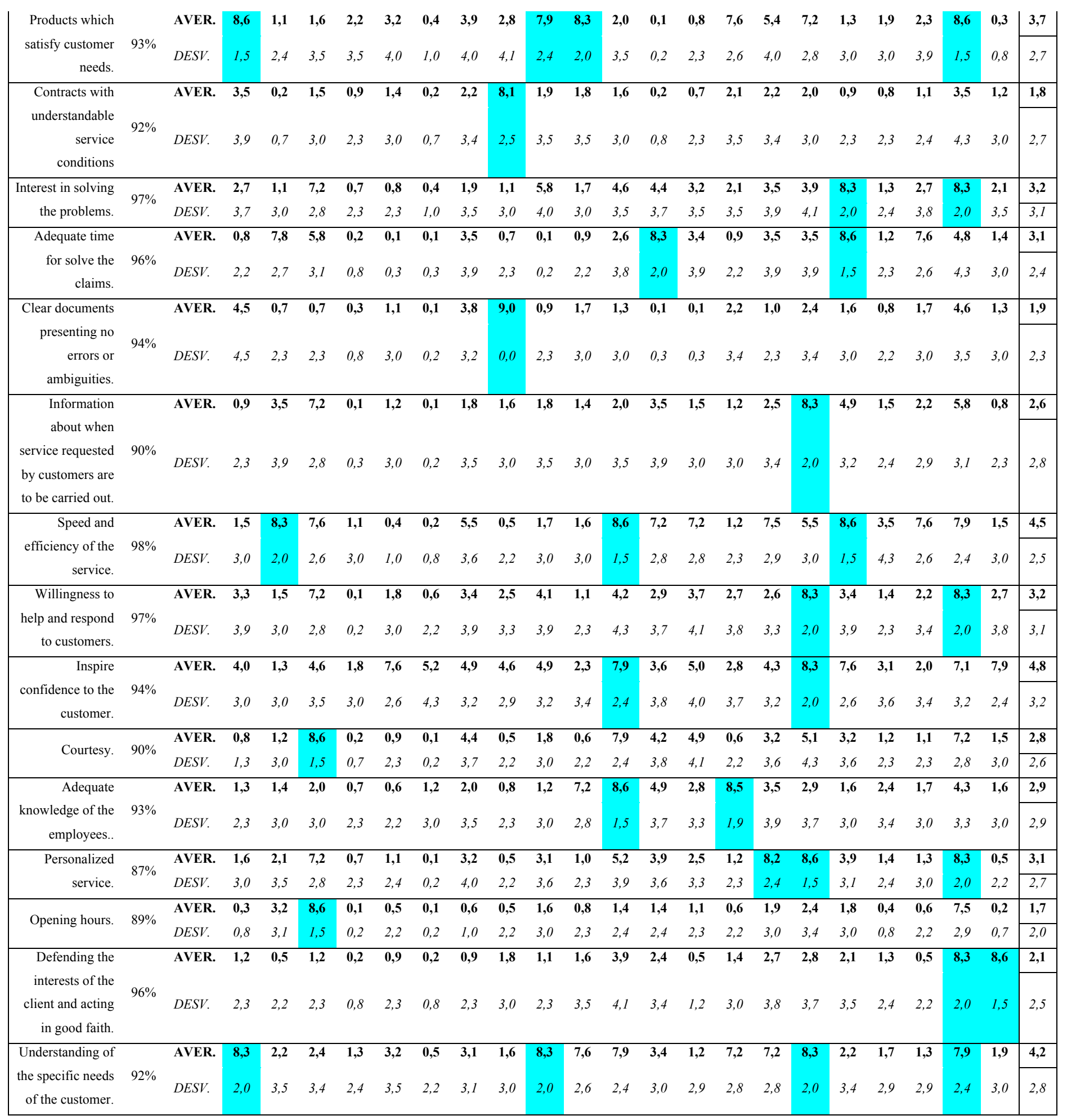

\begin{tabular}{|l|l|l|l|l|l|l|l|l|l|l|l|l|l|l|l|l|l|l|l|l|l|}
\hline Contributions & 55 & 52 & 84 & 25 & 43 & 21 & 56 & 46 & 56 & 48 & 84 & 62 & 50 & 52 & 70 & 93 & 82 & 36 & 47 & 119 & 53 \\
\hline $\begin{array}{c}\text { Contributions } \\
\text { Relative }\end{array}$ & $4 \%$ & $4 \%$ & $7 \%$ & $2 \%$ & $3 \%$ & $2 \%$ & $5 \%$ & $4 \%$ & $5 \%$ & $4 \%$ & $7 \%$ & $5 \%$ & $4 \%$ & $4 \%$ & $6 \%$ & $8 \%$ & $7 \%$ & $3 \%$ & $4 \%$ & $10 \%$ & $4 \%$ \\
\hline
\end{tabular}

Figure 4. Results of ISQFD 
An interesting result shows that by improving "Pricing systems", customers would only perceive improvements in the price. A similar situation appeared when experts were asked to find correlations with improving "Work environment", which would only have an impact on the image of the employees.

\subsection{Contribution of the HOWs}

An important starting point in order to understand the results of the QFD analysis are contribution values. As mentioned earlier, they show the general contributions of the actions a company can improve (HOWs) in the set of service quality items (WHATs).

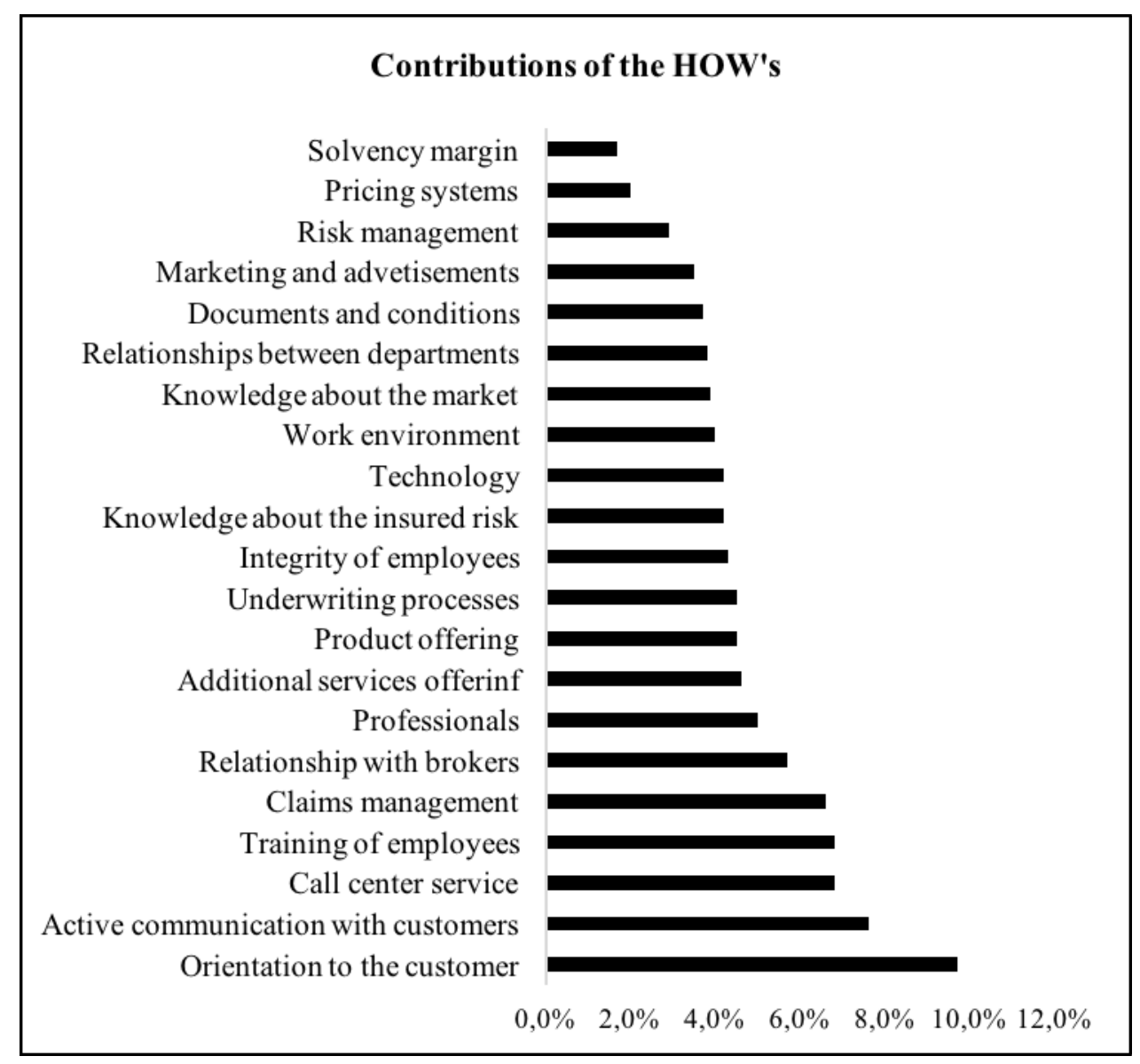

Figure 5. Contribution values

According to the results obtained in Figure 5, it is very clear that "Customer orientation", "Active communication with the customer", "Training of the employees" and "Call center service" and "Claims management" (both have a direct implication on the relationship with the customer) are the most important elements insurance companies should improve so as to obtain better global results in service quality. 
"Solvency margin", "Pricing systems" and "Risk management", on the other hand, are clearly far away from customer service quality perception. Curiously, insurance companies provide these areas using advanced technical resources, but according to the results, they have no direct impact on customer satisfaction.

Results are consistent with recent trends in the Spanish insurance market, which are strongly focused on customers.

It is likely that customers are taking the solvency margin of insurance companies for granted.

\subsection{Results of the Roof}

The Roof in QFD intends to analyze common correlations between future actions in order to improve service quality. It is a useful tool to discover HOWs, which can indirectly help improve the WHATs that do not stand out in the main QFD matrix.

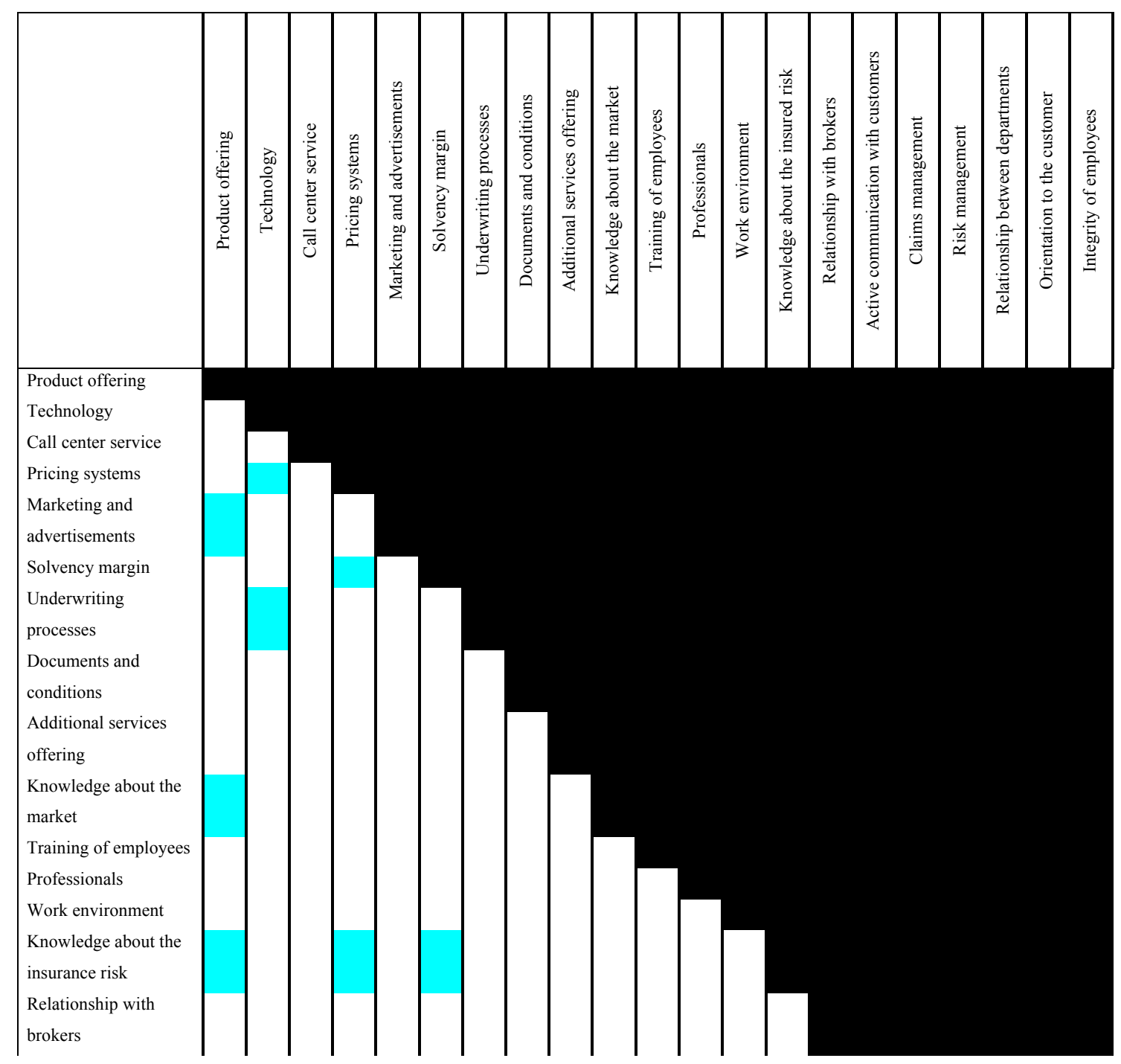




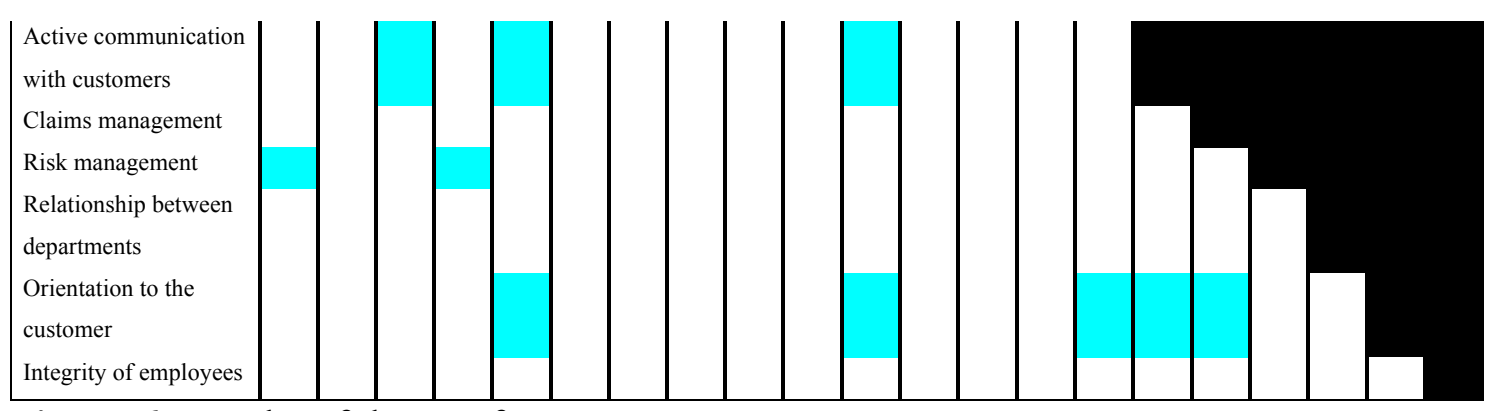

Figure 6. Results of the Roof

Results in Figure 6 show the combination of HOWs. $75 \%$ or more of the interviewed insurance experts agree that there is a correlation.

As expected, "Knowledge about the market", "Relationship between departments" in insurance companies (which is going to be reflected in shared knowledge), and "Marketing" have a correlation with "Product offering" because of communication and knowledge.

Improvements in technology have an impact on pricing systems and underwriting processes. It is a well-known fact that the insurance sector has considerably improved underwriting processes and pricing systems in the past few years thanks to technology. As discussed in previous analyses, customer orientation is important to satisfy customers. Its correlations with efforts in advertisement, training of employees, communication, relationships with brokers and claims management imply that insurance companies could increase customer orientation by improving the traditional points of the insurance business, such as the relationship with the distribution channel and claims management.

\section{Conclusions}

This study offers a significant contribution to academic literature and academic research. Firstly, the ISQFD was specifically developed for the insurance sector for the first time. Secondly, the development of a specific service quality scale for the insurance business (SIQUAL) shows which the most representative and important elements are in service quality for property and casualty insurance customers. Finally, ISQFD has proved to be an important tool to analyze service quality in property and casualty insurance. We have established the basis for future research in insurance service quality, showing how insurance companies can improve important business implications such as-increasing customer retention. 
We have built an empirical basis for researchers in non-life insurance or other intangible services to focus their future investigations on analyzing other important insurance products or lines of business such as life insurance services by applying the ISQFD methodology.

Moreover, this study provides researchers with a set of business and strategic actions actions in order to improve service quality combining the opinions of insurance experts and customer experience, which represents a solid basis for the future.

Taking into consideration the findings of this research, future researches will focus on the most important service characteristics for insurance customers to get additional results.

This research intends to show the significant aspects insurance companies should focus their investments on to improve service quality and competitiveness and, as a result, their sales and customer retention. We found evidence to prove that the most important points are related to service provision. Evidence also shows that the insurance company activities customers value the most are those focused on customer orientation and those providing employees with knowledge and abilities to efficiently interact with customers.

According to the results obtained in the case study by applying the ISQFD, we can conclude that "Orientation to the customer", "Active communication with the customer" and "Training of the employees" are the most important HOWs, and all of them are related to service rather than the insurance product itself.

The results obtained in this research show that an important point to take into account is the importance of the majority of the WHATs analyzed. To conclude, insurance customers have high expectations of service, and there are no significant differences in customer preferences or expectations. This phenomenon shows the continuous pressure insurance companies are under in order to maintain their products and services at levels of quality that are high enough to satisfy their customers.

When interpreting our research findings, the following limitation of the study should be taken into account. Despite the fact that we interviewed numerous experts, more completed questionnaires would have improved the study. However, as the sample did not represent any company in particular, it provided totally unbiased results. 


\section{REFERENCES}

Anderson, F. and Skogh, G. (2003). "Quality, self-regulation, and competition: the case of insurance". Insurance: Mathematics and Economics, 32, 267-280.

Barlow, J. and Moller, C. (2008). A Complaint is a Gift: Recovering Customer Loyalty When Things Go Wrong. Berrett-Koehler Publishers: San Francisco.

Berglund, R.L. (1993). "QFD: a critical tool for environmental decision making". Transactions of the 1993 ASQC Quality Congress, Boston, MA, 593-9, 24-26.

Chan, L.-K. and Wu, M.-L. (2002). "Quality function deployment: a literature review". European Journal of Operational Research, 143, 463-97.

Cristiano, J. J., Liker, J.K. and White, C.C. (2000). "Customer-Driven Product Development through Quality Function Deployment in the U.S. and Japan". Journal of Production Innovation Management, 17, 286-308.

Denove, C. and Power J.D. (2007). Satisfaction: How Every Great Company Listens to the Voice of the Customer. Penguin: New York.

Devadasan, S. R., Kathiravan, N. and Thirunavukkarasu, V. (2006). "Theory and practice of total quality function deployment: A perspective from a traditional pump manufacturing environment". The TQM Magazine, 18(2), 143-161.

Diacon, S. and O'Brien, C. (2002). Persistency in UK Long-Term Insurance: Customer Satisfaction and Service Quality. CRIS Discussion Papers III, University of Nottingham.

Ennew, C.T. and Binks, M.R. (1996). "The impact of service quality and service characteristics on customer retention: small businesses and their banks in the UK". British Journal of Management, 7, 219-30.

Franceschini, F. (2001). Advanced Quality Function Deployment. St. Lucy Press: Boca Raton.

Frank, B. and Enkawa, T. (2007). "How Economic Growth Affects Customer Satisfaction: A Study from Germany". Proceedings of the 13th Asia Pacific Management Conference, Melbourne, Australia, 115-120.

Furrer, O., Liu, B.S.-C. and Sudharshan, D. (2000). "The relationships between culture and service quality perceptions: basis for cross-cultural market segmentation and resource allocation". Journal of Service Research, 2, 355-71.

Gans, N. (2002). "Customer loyalty and supplier quality competition". Management Science, 48, 207-221.

Ghobadian, A., Speller, S. and Jones, M. (1993). "Service quality: concepts and models". International Journal of Quality \& Reliability Management, 11, 43-66. 
Han, C.H., Kim, J.K., Choi, S.H. and Kim, S.H. (1998). "Determination of information system development priority using quality function deployment". Computers \& Industrial Engineering, 35, 241-264.

Harrison, T. (2003). "Understanding the Behavior of Financial Services Consumers: A Research Agenda". Journal of Financial Services Marketing, 8(1), 6-9.

Hauser, J.R. and Clausing, D. (1988). "The house of quality". Harvard Business Review, $66,63-73$.

Joskow PL (1973). "Cartels, competition and regulation in the property liability insurance industry". The Bell Journal of Economics and Management Science, 4(2), 375-427.

King, C. (1992). "Agents/policy owners split on service". National Underwriter, 41(October), 7.

Krishnan, V. and Ulrich, K.T. (2001). "Product development decisions: a review of the literature”. Management Science, 47 (1), 1-21.

Lee, H., Lee, Y. and Yoo, D. (2000). "The determinants of perceived service quality and its relationship with satisfaction". Journal of Services Marketing, 14(3), 217 - 231.

Lombardi, L.J. (2005). “The importance of client retention”. LIMRA's MarketFacts, 24, 31-2.

Moore, J.F. and Santomero, A.M. (1999). "The industry speaks: results of the WFIC Insurance Survey". In Cummins, J.D. and Santomero, A.M. (Eds.). Changes in the Life Insurance Industry: Efficiency, Technology and Risk Management, Kluwer, Norwell.

Parasuraman, A., Zeithaml, V.A. and Berry, L.L. (1988). "SERVQUAL: A MultipleItem Scale for Measuring Consumer Perceptions of Service Quality". Journal of Retailing, 64 (Spring), 12-40.

Peppers, D. and Rogers (2014). Managing Customer Relationships: A Strategic Framework. John Wiley \& Sons: New Jersey.

Pfohl, H.C. and Ester, B. (1999). "Benchmarking for spare parts logistics". Benchmarking: An International Journal, 6 (1), 22-45.

Philips, M., Sander, P. and Govers, C. (1994). "Policy formulation by use of QFD techniques: a case study". International Journal of Quality \& Reliability Management, $11(5), 46-58$.

Pointek, S. (1992). "Outside interests: making the move from lip service to real service". National Underwriter, 96(44), 34.

Roberts, J.H. (2005). "Defensive Marketing: How a Strong Incumbent Can Protect Its Position". Harvard Business Review, 83(11), 150-155.

Roos, C.M. (1981). “On insurer generosity”. Scandinavian Studies in Law, 25, 152-165. 
Shlesinger, H. and Graf von der Shulenburg, J.M.G. (1993). "Consumer information and decisions to switch insurers". Journal of Risk \& Insurance, 60 (4).

Stratton, B. (1989). “The refined focus of automotive quality”. Quality Progress, 2 (10), 47-50.

Sullivan, L.P. (1986). "Quality function deployment”. Quality Progress, 19, 39-50.

Taylor, S. A. (2001). "Assessing the use of regression analysis in examining service recovery in the insurance industry: relating service quality, customer satisfaction and customer trust". Journal of Insurance Issues, 24 (1/2), 30-57.

Terninko, J. (1995). Step-by-Step, Q.F.D. Customer Driven Product Design. American Supplier Institute, Dearborn, MI.

Toran, D. (1993). “Quality service (quality everything!)”. LIMRA'S Market Facts, 12 (2), 10-11.

Tsoukatos, E. and Rand, G. (2006). "Path analysis of perceived service quality, satisfaction and loyalty in Greek insurance". Managing Service Quality, 16, 501-519.

Tsoukatos, E., Marwaa, S. and Rand, G. (2004). "Diagnosis and Improvement of Service Quality in the Insurance Industries of Greece and Kenya". Journal of LUMS England, 124.

Walker, J. and Baker, J. (2000). “An exploratory study of a multi-expectation framework for service”. Journal of Service Marketing, 14(5), 411-431.

Wells B.P. and Stafford, M.R. (1997). "Insurance education efforts and insurer service quality”. Journal of Insurance Regulation, 15(4), 540-547.

Zairi, M. and Youssef, M.A. (1995). "Quality function deployment - a main pillar for successful total quality management and product development". International Journal of Quality \& Reliability Management, 12, 9-23.

Zeithaml, V.A. and Bitner, M.J. (1996). Services Marketing. McGraw-Hill: New York.

Zeithaml, V.A., Berry, L.L. and Parasuraman, A. (1988). "Communication and control processes in the delivery of service quality". Journal of Marketing, 52(2), 35-48. 